\title{
Small variable segments constitute a major type of diversity of bacterial genomes at the species level
}

Fabrice Touzain ${ }^{1}$, Erick Denamur ${ }^{2}$, Claudine Médigue ${ }^{3}$, Valérie Barbe ${ }^{4}$, Meriem El Karoui ${ }^{1}$, Marie-Agnès Petit ${ }^{*}$

\begin{abstract}
Background: Analysis of large scale diversity in bacterial genomes has mainly focused on elements such as pathogenicity islands, or more generally, genomic islands. These comprise numerous genes and confer important phenotypes, which are present or absent depending on strains. We report that despite this widely accepted notion, most diversity at the species level is composed of much smaller DNA segments, 20 to $500 \mathrm{bp}$ in size, which we call microdiversity.

Results: We performed a systematic analysis of the variable segments detected by multiple whole genome alignments at the DNA level on three species for which the greatest number of genomes have been sequenced: Escherichia coli, Staphylococcus aureus, and Streptococcus pyogenes. Among the numerous sites of variability, 62 to $73 \%$ were loci of microdiversity, many of which were located within genes. They contribute to phenotypic variations, as 3 to $6 \%$ of all genes harbor microdiversity, and 1 to $9 \%$ of total genes are located downstream from a microdiversity locus. Microdiversity loci are particularly abundant in genes encoding membrane proteins. In-depth analysis of the E. coli alignments shows that most of the diversity does not correspond to known mobile or repeated elements, and it is likely that they were generated by illegitimate recombination. An intriguing class of microdiversity includes small blocks of highly diverged sequences, whose origin is discussed.

Conclusions: This analysis uncovers the importance of this small-sized genome diversity, which we expect to be present in a wide range of bacteria, and possibly also in many eukaryotic genomes.
\end{abstract}

\section{Background}

The availability of bacterial genome sequences for closely related strains within a species and software dedicated to multiple genome alignments allow for a novel perspective of bacterial genetic diversity [1-3]. Use of these aligners has led to the notion that bacterial species share a DNA backbone common to all strains interrupted by variable segments (VSs) that are specific to a subset of the aligned strains [4-6]. The most studied category of VSs are genomic islands, which are defined by Vernikos and Parkhill as horizontally acquired mobile elements of limited phylogenetic distribution [7]. These islands are of a large size (30 to $100 \mathrm{~kb}$ ), and often encode genes critical for pathogenesis [8]. Their integration into genomes presumably occurs by site-specific

\footnotetext{
* Correspondence: marie-agnes.petit@jouy.inra.fr

${ }^{1}$ INRA, UMR1319, Micalis, Bat 222, Jouy en Josas, 78350, France
}

recombination. Genomic islands may then diffuse from strain to strain by homologous recombination [9]. Where known, horizontal transfer of islands occurs either by mobilization through bacteriophages, such as in Staphylococcus aureus [10,11] or by conjugation, using transfer origins located either outside or inside the island $[9,12,13]$. Informatic tools have been developed to detect such islands in genomes [14-16]. A second category of VSs of large size involves temperate bacteriophages, or phage remnants. Like genomic islands, they enter the bacterial chromosome by site-specific recombination. Informatic tools to predict these elements have flourished in the past few years [17-19]. Recently, a new class of large variable elements has been characterized with the clustered, regularly interspaced short palindromic repeats (CRISPR), in which repeats alternate with short DNA segments of plasmid or bacteriophage origin. These regions confer phage or plasmid immunity $[20,21]$
C Biomed Central

C 2010 Touzain et al.; licensee BioMed Central Ltd. This is an open access article distributed under the terms of the Creative Commons Attribution License (http://creativecommons.org/licenses/by/2.0), which permits unrestricted use, distribution, and reproduction in any medium, provided the original work is properly cited. 
by mechanisms that remain to be understood. Databases for these elements are available [22,23]. Transposons and insertion sequences (ISs) also contribute to VSs when closely related genomes are compared, and their size is small compared to the first two types of elements (a few hundred base pairs to a few kilobases). These elements move within a given genome by transposition. A reference website allowing their classification exists [24], and two strategies for automated IS detection have been described $[25,26]$. Finally, the smallest kind of VS (with $\mathrm{a}=20 \mathrm{bp}$ threshold) expected to be present when genomes are aligned are the minisatellites, composed of small tandem repeats that are commonly used for strain typing. Websites allowing their recognition are available [27-29]. A special category of such repeats are the 'small dispersed repeats', some 20 bp long and tandemly repeated in various copy numbers in genomes, which might be mobile [29]. The Escherichia coli genomes contain a family of such elements, called palindromic units (PUs; 30 to $37 \mathrm{bp}$ ), which are palindromic and intergenic, and often combined in clusters [30].

DNA recombination and mutagenesis are the sources of respectively large and small scale genetic diversity in genomes. In a broad sense, recombination designates all events that reshuffle DNA sequences. This reshuffling can have two opposite effects: either it homogenizes DNA sequences (a process called DNA conversion), or it provokes the abrupt loss, acquisition or translocation of genetic information, and therefore brings in diversity. A wide range of artificial genetic systems have been set up in the past decades to study recombination at the molecular level in bacteria and to determine the frequencies of its occurrence. Among the three main categories of recombination events, site-specific recombination is highly efficient; for example, recombination can occur in $100 \%$ of cells in an engineered site-specific recombination assay [31]. However, this class of events is limited by its specialization, as it requires a dedicated enzyme (whose expression is usually regulated) and its cognate site. The next most efficient bacterial system is homologous recombination; for example, an estimated $10^{-4}$ of a non-stressed cell population recombined 1-kb-long tandem repeats present in the chromosomes of Salmonella typhimurium [32], E. coli [33], Bacillus subtilis [34] and Helicobacter pylori [35]. These events usually rely on RecA, an ubiquitous enzyme that catalyzes homologous DNA pairing. Homologous recombination is not sequence-specific, and its efficiency is proportional to the length of homology shared by the recombining molecules. High proportions of recombinants are scored during DNA conjugation (up to 10\%), where several hundred-kilobase-long DNA segments enter the cell [36], and during natural DNA transformation [37]. Finally, illegitimate recombination is the least efficient mode of recombination, with events occurring in approximately $10^{-8}$ of a given cell population [38,39]. It includes events that join DNA segments not sufficiently homologous for RecA pairing, nor involved in site-specific recombination. Illegitimate recombination events are attributed to errors of enzymes that deal with DNA, such as DNA polymerases [40-42], RNA polymerases [43], repair enzymes, or topological enzymes (for reviews, see [44,45]). Interestingly, the non-homologous end joining type of illegitimate recombination, which involves dedicated enzymes and has a pre-eminent role in eukaryotes, is almost absent in prokaryotes, except in a few species such as Mycobacterium tuberculosis $[46,47]$ and B. subtilis, where it contributes to spore germination and resistance to desiccation $[48,49]$.

To date, no correlation exists between experimental DNA recombination studies and comparative genomic analyses. Indeed, molecular analyses usually focus on a single type of event (for examples, see $[34,38,42]$ ) without considering its frequency compared to those of other events that occur in the natural history of bacterial genomes. It is conceivable that the least efficient - that is, illegitimate recombination - is the major contributor in shaping bacterial genomes. Comparative genomic analyses offer the possibility to examine genome diversity globally, but most studies usually concentrate on just a single class of VSs. One exception involves a systematic analysis of all VSs of more than 10 bp present on two very closely related $S$. aureus genomes [50]. Among 27 VS sites, this study revealed a pre-eminence of illegitimate events over other classes of recombination, and raises questions of whether this observation can be generalized to more diverse genomes, and to other species.

In this report, we performed multi-strain alignments in three very different species to make a global assessment of bacterial diversity. Our aim was to understand the kind of molecular events that shaped present day genomes, and to determine the features of recombination. Our main finding is that short VSs (20 to $500 \mathrm{bp}$ long) are highly frequent in genomes and reside often within genes. Such VSs are sometimes referred to as indels, but our multigenome analysis shows that only a minority of them originates effectively from an insertion or a deletion; we therefore designated them collectively by the broader term of 'microdiversity'. This study uncovers the numerical importance of microdiversity, predicts the pre-eminence of illegitimate recombination as the mechanism generating it, and highlights the existence, among microdiversity, of highly diverged blocks.

\section{Results}

\section{Strain choice}

E. coli, S. aureus and Streptococcus pyogenes were selected to examine intra-species diversity at the 
genome level, as they are the three species with the greatest number of available genome sequences. Members of each species are known pathogens, but otherwise they have very diverse characteristics: $E$. coli is a Gramnegative bacterium that lives both in the digestive tract of warm blooded animals and in water, while S. aureus and S. pyogenes are Gram-positive species that respectively colonize the nose, and skin and throat of mammals. Unlike the two other species, S. pyogenes is an obligate fermenting bacterium. Five genomes representative of each of these species were selected such that each member of the set was as distant as possible from all others (see Materials and methods). The E. coli species is particularly diverse, and phylogenetic studies led to the conclusion that a branch of this species, the B2 phylogenetic group, behaves as a subspecies [51,52]. Moreover, the comparative study of $20 \mathrm{E}$. coli genomes identified a substantial set of genes that are unique to the $\mathrm{B} 2$ group [53]. We therefore analyzed a set of five E. coli $\mathrm{B} 2$ genomes as a group, in addition to the genome set representative of the $E$. coli species. Neighbor joining trees derived from a new genomic distance called MUMi (see Materials and methods) [54] were calculated for the four strain sets (Figure 1). The E. coli MUMi tree was congruent with the phylogenetic tree reconstructed from the Escherichia core genome genes [53]. As for the S. aureus and S. pyogenes sets, reliable phylogenetic trees derived from the concatenated core genome of the species are not yet available to our knowledge, but our previous results suggest that the MUMi trees should be good approximations of phylogenetic trees [54].

To complete the five genomes analyses, alignments involving a maximum number of genomes were also analyzed using 25, 11 and 12 genomes for E. coli, S. aureus

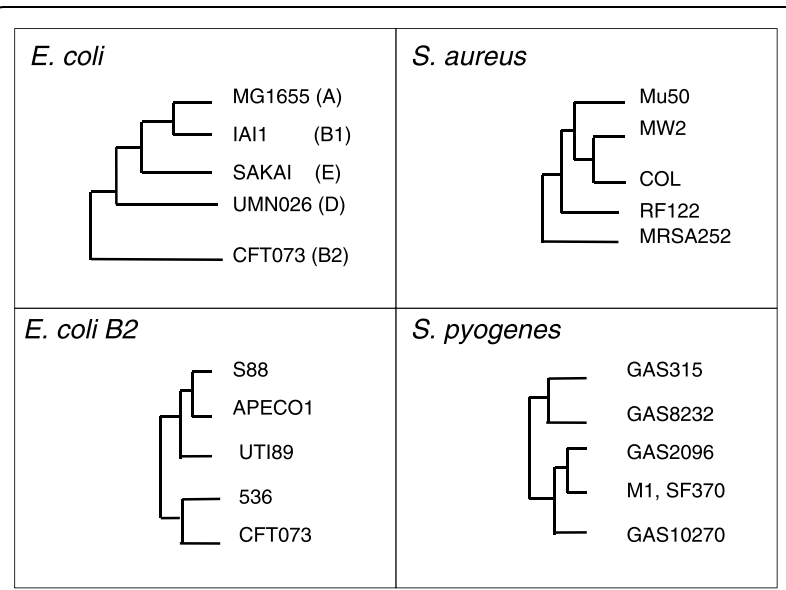

Figure 1 Neighbor joining trees based on genomic MUMi distances of the strains selected for the five-genome alignments.

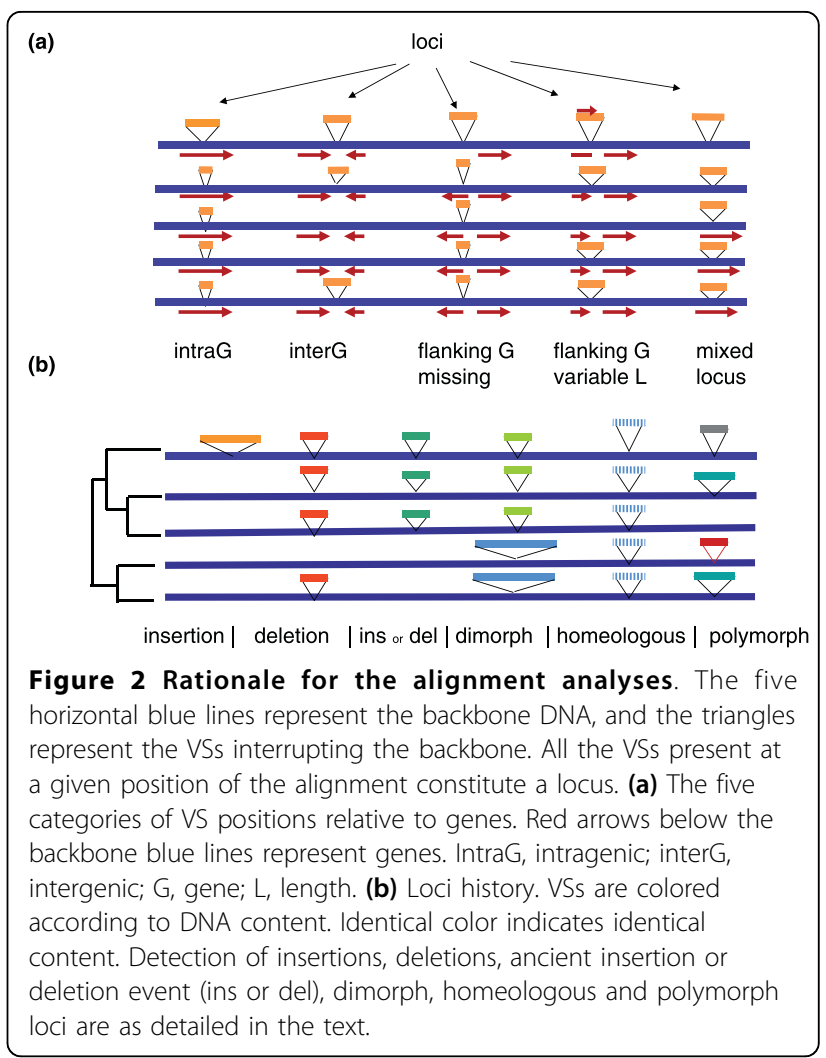

and S. pyogenes, respectively. Trees of the strains used are shown in Additional file 1.

\section{Alignments and definition of the variable segments}

Complete multiple genome aligners provide general outlines of colinear regions among the genomes, as well as the set of identical anchors (short DNA fragments) shared by all genomes. Out of these data, complete alignments can be defined precisely using a post-treatment step, so as to attribute which parts of the genomes belong to the common backbone DNA, and which parts are VSs (see Materials and methods). MOSAIC [55] is a database offering such completely refined alignments for bacterial genomes at the intra-species level, using either MGA or MAUVE as entry points for the post-treatment step. We have shown previously $[4,5]$ that it is possible to use robust criteria to delineate VSs: if in a part of the alignment at least two DNA segments differ by more than $24 \%$ at the nucleotide level, or if the alignment includes a gap of at least 20 nucleotides, all segments of this part of the alignment are labeled as VSs. Further details on these parameter choices are given in the Materials and methods and in Additional file 2.

VSs are defined here as DNA segments with a minimum length of $20 \mathrm{bp}$, and that differ from one another at a given position of the alignment. The cutoff chosen to decide that two VSs differ from one another is largely 
Table 1 Characteristics of the four whole-genome alignments, involving five strains each

\begin{tabular}{|c|c|c|c|c|}
\hline & E. coli & E. coli B2 & S. aureus & S. pyogenes \\
\hline $\begin{array}{l}\text { Median genome size } \\
\text { (Mb) }\end{array}$ & 5.2 & 5.2 & 2.8 & 1.8 \\
\hline Maximal MUMi distance & 0.3 & 0.156 & 0.197 & 0.175 \\
\hline Coverage $^{a}$ & $72.7 \%$ & $83.5 \%$ & $84.5 \%$ & $83.5 \%$ \\
\hline $\begin{array}{l}\text { Percent identity of } \\
\text { backbone }\end{array}$ & $98.05 \%$ & $99.43 \%$ & $98.73 \%$ & $99.18 \%$ \\
\hline Total number of locib & 1,037 & 539 & 768 & 344 \\
\hline $\begin{array}{l}\text { Number of } \\
\text { microdiversity loci }\end{array}$ & 640 & 370 & 556 & 250 \\
\hline Median size of VS $(b p)^{c}$ & 93 & 68 & 78 & 61 \\
\hline
\end{tabular}

aproportion of the genome included in the backbone (average). ${ }^{\mathrm{b}}$ Positions in the alignment where the backbone is interrupted by at least one variable segment (VS).

above the average pairwise nucleotide diversity between orthologous genes, which usually does not exceed 5\% at the intra-species level in bacteria. As a consequence, in this analysis, all sequences having point mutations corresponding to the intra-species vertical divergence, as well as small indels, are classified as the backbone and are not considered.

The main characteristics of the alignments are presented in Table 1 . While the E. coli strains were, as expected, more distantly related to one another than strains of the other sets [54] (see the longer branches in Figure 1, and maximal MUMi values in Table 1), the B2E. coli, S. pyogenes and $S$. aureus sets had similar 'tree depth', suggesting that these three sets diverged during similar evolutionary time scales.

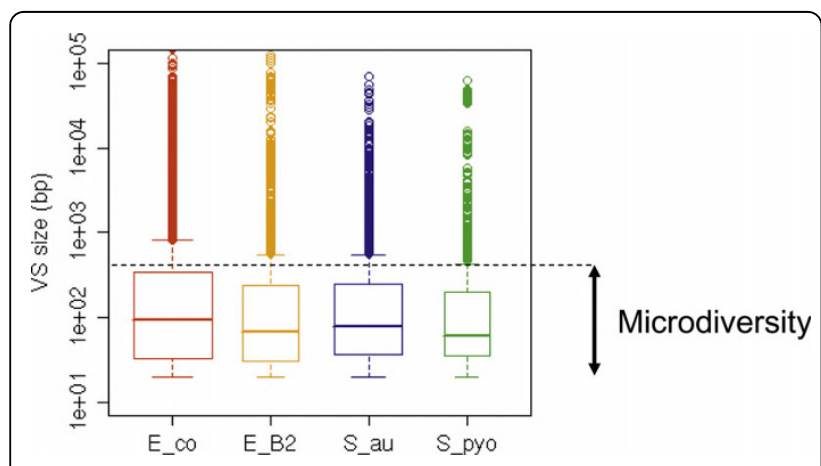

Figure 3 Size distribution of the variable segments produced in the four alignments (box plots). Each box shows the median value (middle lane), first and third quartiles (lower and upper lanes) of the size distribution. Values laying more than 1.5 times the interquartile value away from the bulk of all values are shown individually as dots. The width of each box is proportional to the number of VSs analyzed per alignment. On the right side, VSS shorter than 500 bp are designated by microdiversity. Abcissa: E_co, E. coli; E_B2, E. coli B2 phylogenetic group; S_au, S. aureus; S_pyo, S. pyogenes.
VSs are abundant, short in size, and, for the most part, different from previously reported variable elements We will hereafter refer to 'locus' as the position of an alignment where the backbone is interrupted by a VS in at least one strain (Figure 2). The number of loci in a given alignment varied from 344 to 1,037 depending on the species studied (Table 1). The VS size distribution in all four alignments is represented as a box-plot in Figure 3, and whole distributions are shown in Additional file 3. A remarkable feature of all the alignments was that most of the segments were small: the VSs had a median size of 60 to $90 \mathrm{bp}$ (Table 1), and at least $75 \%$ of all VSs were smaller than 500 bp (Figure 3). Loci where all VSs were less than $500 \mathrm{bp}$ long were also abundant (62 to $73 \%$ of all loci; Table 1), and will be designated hereafter as microdiversity loci. To test whether microdiversity was still present when more genomes are aligned, alignments of $E$. coli, S. aureus and $S$. pyogenes using 25, 11 and 12 genomes, respectively, were realized (Table 2). Overall, the number of loci increased by $50 \%$ for $E$. coli, $26 \%$ for S. aureus, and $65 \%$ for $S$. pyogenes. Again, microdiversity loci represented 55 to $78 \%$ of all loci. We conclude that the most abundant type of genomic diversity is microdiversity, irrespective of the number of genomes included in the alignment.

Given the abundance of annotated data available for E. coli in databases, we selected this species to perform a mapping of the VSs to available annotations such as bacteriophages, genomic islands, clustered, regularly interspaced short palindromic repeats (CRISPRs), ISs, and repeated elements such as minisatellites and PUs (see Materials and methods for data collection). If more than $50 \%$ of the length of a VS corresponded to an annotated region, the VS was labeled as such. All VS labels were then stored collectively at the locus level. The number of loci containing each type of annotation is reported (Table 3 ). Only $35 \%$ of the 1,037 loci of the E. coli alignment, and $47 \%$ of the B2 subgroup loci, corresponded to one of the elements described above. Therefore, the major proportion of the loci does not originate from readily identifiable events. In particular, the microdiversity loci accounted for 63 to $72 \%$ of the category 'Other'. The DNA content of the E. coli loci not belonging to known categories was compared by Blast to the Non-Redundant database (see Materials and methods). The largest category comprised segments that matched with other $E$. coli strains (65 to $86 \%$ of the cumulated DNA length of all VSs tested in a given genome). This suggests that most of the VSs belong to a shared pool of E. coli sequences, the so-called E. coli pan-genome. The next largest category included segments that did not have any match in the database (13 to $34 \%)$. DNA segments matching to other species or 
Table 2 Microdiversity loci, including homeologous and dimorphic loci, are dominant categories irrespective of the number of genomes aligned

\begin{tabular}{lcccccc}
\hline & \multicolumn{2}{c}{ E. coli } & \multicolumn{2}{c}{ S. aureus } & \multicolumn{2}{c}{ S. pyogenes } \\
\hline Number of genomes aligned & 5 & 25 & 5 & 11 & 5 & 12 \\
Total number of loci & 1,037 & 1,553 & 768 & 970 & 344 & 570 \\
Number of microdiversity loci (M) & $640(62 \%)^{\mathrm{a}}$ & $852(55 \%)$ & $556(72 \%)$ & $715(74 \%)$ & $250(73 \%)$ & $385(67 \%)$ \\
Insertions/M & $7.03 \%$ & $3.99 \%$ & $3.6 \%$ & $1.12 \%$ & $4.8 \%$ & $5.71 \%$ \\
Deletions/M & $4.22 \%$ & $4.69 \%$ & $4.68 \%$ & $4.48 \%$ & $12.4 \%$ & $10.91 \%$ \\
Insertions or deletions/M & $3.59 \%$ & $0.47 \%$ & $3.24 \%$ & $2.66 \%$ & $0.8 \%$ & $0 \%$ \\
Dimorphs/M & $37.97 \%$ & $23.71 \%$ & $42.63 \%$ & $52.03 \%$ & $31.6 \%$ & $22.34 \%$ \\
Homeologous/M & $30.31 \%$ & $45.89 \%$ & $22.84 \%$ & $23.5 \%$ & $19.6 \%$ & $27.53 \%$ \\
Polymorphs/M & $16.88 \%$ & $21.24 \%$ & $23.02 \%$ & $16.22 \%$ & $30.8 \%$ & $33.51 \%$ \\
\hline
\end{tabular}

apercentage of total loci.

Table 3 Number of loci in E. coli alignments corresponding to known elements

\begin{tabular}{|c|c|c|c|c|c|c|c|c|}
\hline & \multicolumn{4}{|c|}{ E. coli } & \multicolumn{4}{|c|}{ E. coli B2 } \\
\hline & \multicolumn{2}{|c|}{ All loci } & \multicolumn{2}{|c|}{ Microdiversity loci } & \multicolumn{2}{|c|}{ All loci } & \multicolumn{2}{|c|}{ Microdiversity loci } \\
\hline & $n$ & Percent & $\mathrm{n}$ & Percent & $\mathrm{n}$ & Percent & $n$ & Percent \\
\hline Total & 1,037 & 100 & 640 & 100 & 539 & 100 & 370 & 100 \\
\hline Bacteriophages & 27 & 3 & 0 & 0 & 35 & 6 & 12 & 3 \\
\hline CRISPR & 3 & 0.3 & 1 & 0.1 & 3 & 2 & 1 & 0.2 \\
\hline Genomic islands & 127 & 12 & 61 & 10 & 103 & 19 & 64 & 17 \\
\hline Insertion sequences & 55 & 5 & 2 & 0.3 & 48 & 9 & 8 & 2 \\
\hline Palindromic units & 129 & 12 & 105 & 16 & 44 & 8 & 37 & 10 \\
\hline Minisatellites & 18 & 2 & 12 & 2 & 17 & 3 & 15 & 4 \\
\hline Other & 678 & 65 & 459 & 72 & 289 & 53 & 233 & 63 \\
\hline
\end{tabular}

CRISPR, clustered, regularly interspaced short palindromic repeat.

environmental samples were essentially absent. In conclusion, most of the variable loci are microdiversity loci, and to the best of our knowledge for E. coli, they do not correspond to known elements, although most contain pan-genomic DNA.

\section{Identification of the microdiversity regions possibly affecting genes}

The remaining part of this analysis focuses on the microdiversity loci that correspond to largely unknown aspects of genome diversity. We chose to focus on the five-genome alignments because more information was available for these. We asked how microdiversity regions were located respective to genes. A microdiversity locus was designated as an 'intragenic locus' if all VSs of the locus were located inside a gene, without perturbing its reading frame, and as an 'intergenic locus' if all VS boundaries were located outside genes (Figure 2a, first two examples). We also considered the cases where insertion of a VS interrupts a gene in at least one strain of the alignment (such as with IS insertions), and called this category 'flanking gene missing' (Figure 2a, third case). Addition of DNA can also sometimes provoke an in-frame fusion, resulting in a locus where VSs have 'flanking genes of variable length'. Finally, we placed the remaining loci in the 'mixed locus' category (it can correspond, for instance, to loci where some VSs of a given locus are intragenic and others intergenic).

Thirty-five to $55 \%$ of the microdiversity loci were intragenic (Figure 4), and did not perturb the reading frame of the gene (for example, see the nucleotide sequence of a 61-bp microdiversity locus present in the $\operatorname{man} Z$ gene; Figure 5). The number of genes affected by microdiversity, that is, harboring a VS in at least one genome, was then calculated. Depending on the genome and the alignment, their proportion ranged from 3 to $6 \%$ of all genes. Some genes contained more than one VS. Remarkably, some $S$. aureus genes harbor up to seven in-frame VSs. These $S$. aureus VS-rich genes encode surface proteins such as the fibrinogen binding protein SdrE, or clumping factor ClfB. The most VS-rich gene of E. coli and B2 subgroup alignments is ftsK (four and three VSs, respectively), encoding a membrane protein important for chromosome segregation. In most cases (75 to $92 \%$ of intragenic loci), the amino acid sequence of the protein was modified by the presence of the VS. Complete lists of these genes are given in Additional files 4, 5, 6 and 7, with a break-down according to functional categories for E. coli genes in Additional file 8. Genes encoding 


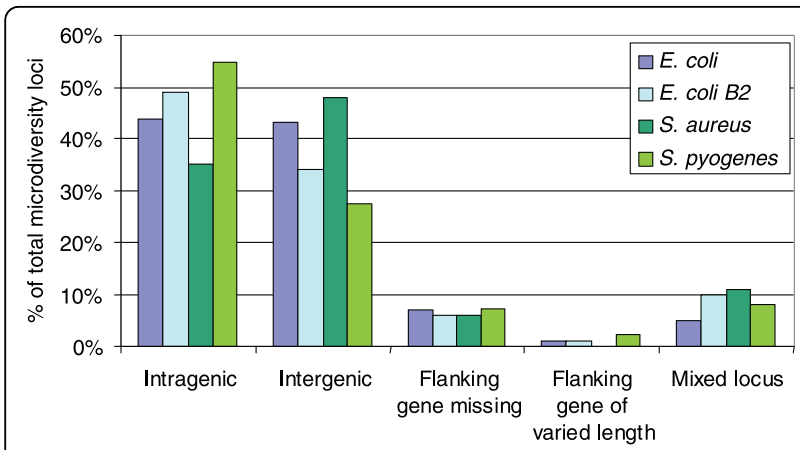

Figure 4 Location of the variable segments relative to genes in the four alignments. The proportion of each category is given as percentages of total loci present in each alignment.

membrane proteins were significantly enriched among the population of genes with microdiversity loci in the E. coli and B2 lists (Additional file 8). These results suggest that besides point mutations, genes also evolve by more abrupt, 'block modifications' of gene fragments (see Discussion).

Intergenic loci represented 23 to $48 \%$ of all loci (Figure 4). In E. coli, some of them corresponded to PU/ repetitive elements (93 of 276 for the global E. coli alignment, and 32 of 127 for the E. coli B2 subgroup alignment). In the $S$. aureus alignment, the intergenic loci were the most abundant, representing $48 \%$ of all variable loci. Some of them likely correspond to Staphylococcus repetitive elements [56] that are intergenic, or to staphylococcal interspersed repeats units [57]. An analysis was performed on loci where VSs were located less than 500 bp upstream of an ORF (Additional files 9, 10,11 , and 12), and a break-down in functional categories was effected for the $E$. coli genes (Additional file 13). The proportion of genes preceded by a VS ranged from 1 to $9 \%$ of all genes. Non-coding RNA (corresponding to tRNA, rRNA and small non-coding RNA) were significantly enriched among the genes preceded by a VS (Additional file 13). Note that these RNA were

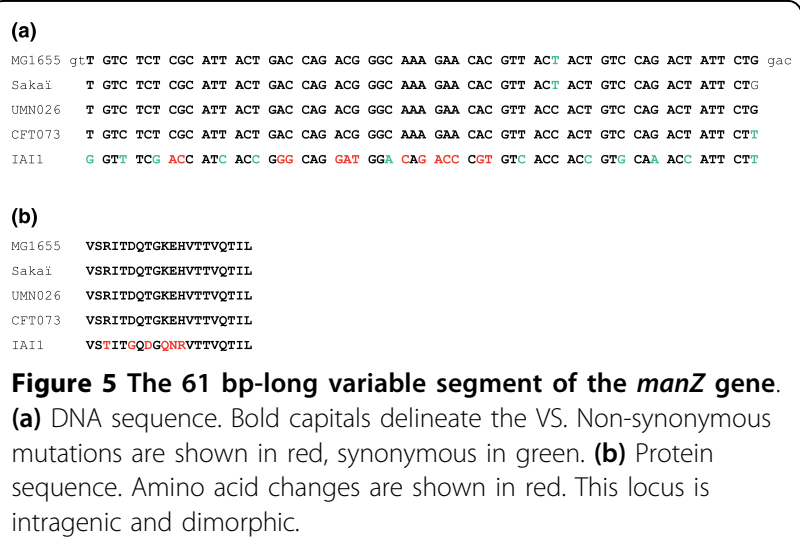

Figure 5 The 61 bp-long variable segment of the manZ gene. (a) DNA sequence. Bold capitals delineate the VS. Non-synonymous mutations are shown in red, synonymous in green. (b) Protein sequence. Amino acid changes are shown in red. This locus is intragenic and dimorphic.

not target sites for genomic island integration, which preferentially integrate downstream from tRNAs. They often corresponded to variations in runs of tRNA genes, or in tRNA interspersed between rRNA genes. Apart from this special category, we suspect that the presence of VSs upstream of genes may affect regulation, and hence contribute to strain diversity.

The mixed loci (5 to $10 \%$ of all loci) correspond generally to cases where the VSs are either intragenic or intergenic. This suggests mutagenic insertion of a DNA sequence inside a gene, leading to its pseudogenization in the strains where the locus is intergenic. Some additional cases of pseudogenization may be detected in loci with a flanking gene missing (5 to $7 \%$ of all loci; Figure 4), if the gene loss is due to the introduction of the VS.

\section{Some $10 \%$ of the VSs are flanked by direct repeats in the microdiversity loci}

Recombination between directly oriented repeats placed at the base of the VS may explain one mechanism of variability: in some strains, a deletion may have occurred between repeats, thereby generating a new locus in the alignment. The percentage of VSs flanked by repeats varied between 10 and $18 \%$, with the highest frequency occurrence in $S$. aureus (Table 4, first part). The vast majority (66 to $94 \%$ ) of repeat sequences were less than 30 bp in size.

If repeats are responsible for instability, one would expect to find genomes in which the VS is deleted. Loci at which at least one of the VSs was flanked by repeats were designated ' $r$-loci' (Table 4, second part). Among these $\mathrm{r}$-loci, the proportion of those where at least one genome had an empty VS at the locus (empty VS means the VS is absent or less than $20 \mathrm{bp}$ long) could be calculated (Table 4, last lines). For the E. coli and S. pyogenes alignments, this proportion was 42 to $66 \%$, which is significantly higher than expected $(P<0.01)$. For $S$. aureus, the proportion of $\mathrm{r}$-loci with apparent deletions was only $16 \%$, which is even less than the overall proportion of loci with apparent deletions (22\%). We conclude that for the r-loci, variability may be explained in part by recombination between these repeats; these events appear to be more frequent in E. coli and S. pyogenes than in S. aureus. Overall, up to one-fifth of the microdiversity between genomes may be due to recombination between short repeats flanking some of the VSs.

\section{Global prediction of loci history reveals two important categories of events: dimorphic loci, and highly divergent loci}

A global analysis was carried out to investigate the possible history of loci and assess the contribution of deletions, insertions, and more complex situations. This 
Table 4 Characteristics of microdiversity loci flanked by repeats

\begin{tabular}{|c|c|c|c|c|}
\hline & E. coli & E. coli B2 & S. aureus & S. pyogenes \\
\hline \multicolumn{5}{|l|}{ VS analysis } \\
\hline $\begin{array}{l}\text { VS flanked by } \\
\text { repeats/all VS }\end{array}$ & $10 \%$ & $14 \%$ & $18 \%$ & $12 \%$ \\
\hline $\begin{array}{l}\text { Repeats less } \\
\text { than } 30 \text { bp/all } \\
\text { vs with repeats }\end{array}$ & $74 \%$ & $66 \%$ & $82 \%$ & $94 \%$ \\
\hline \multicolumn{5}{|l|}{ Loci analysis } \\
\hline $\begin{array}{l}\text { Total number of } \\
\text { loci }\end{array}$ & 640 & 370 & 556 & 250 \\
\hline $\begin{array}{l}\% \text { of loci with } \\
\text { VSs flanked by } \\
\text { repeats (r-loci)/ } \\
\text { all loci }\end{array}$ & $21 \%$ & $22 \%$ & $32 \%$ & $23 \%$ \\
\hline $\begin{array}{l}\text { \% loci with } \\
\text { possible } \\
\text { deletion/r-loci }\end{array}$ & $51 \%$ & $66 \%$ & $16 \%$ & $42 \%$ \\
\hline $\begin{array}{l}\text { \% loci with } \\
\text { possible } \\
\text { deletion/all loci }\end{array}$ & $21 \%$ & $25 \%$ & $22 \%$ & $20 \%$ \\
\hline
\end{tabular}

implied the analysis of VS content, placed within a phylogenetic context. Our approach consisted first in assigning an 'occupancy' value to all loci. It corresponds, for a given locus, to the number of genomes that 'occupy' the locus, that is, where the VS is not empty. We observed that 75 to $80 \%$ of loci had maximal occupancy, that is, occupancy 5 (Additional file 14).

We then made use of locus occupancy, strain phylogeny and VS content to predict some simple situations, using the parsimony principle (Figure $2 \mathrm{~b}$ ): loci of occupancy 1 with VSs on a short branch were predicted to be 'recent insertions', while loci of occupancy 4 with identical VS content and the longer branch occupied were predicted as 'recent deletions'. Using a similar method, loci of occupancy 2 or 3 with VSs of identical content present on the same sub-tree, were predicted as 'ancestral insertions or ancestral deletions'. Among the loci of maximal occupancy, two situations were singled

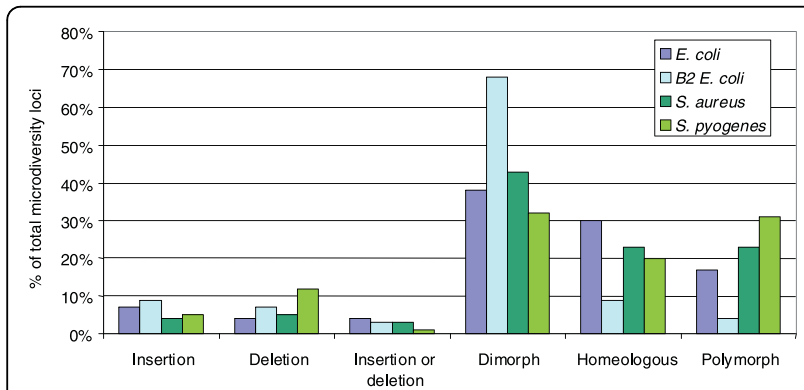

Figure 6 Prediction of locus histories in the four alignments. The proportion of each category is given as percentages of total loci present in each alignment. out: loci with only two kinds of VS segregating on subtrees, which were named 'dimorphs'; and loci where all VSs turned out to be of nearly identical content, which were named 'homeologs'. These loci may indicate places where DNA diverges more rapidly than elsewhere on the genome, and they were therefore kept in the 'VS pool'. The last category of 'polymorphs' included all other loci.

Results showing the proportions of loci encountered in each category are reported in Figure 6. Surprisingly, the 'dimorphs', in which a given locus contains exactly two different kinds of segment, was the most abundant category. Dimorphic loci can be explained by the presence of a DNA insertion hot spot or by the replacement of an 'ancestral' sequence by a new segment. If such is the case, it should be possible to match one of the two VSs of the locus with a genome segment of a closely related species. A Blast analysis was conducted for the E. coli and B2 phylogenetic group alignments on all dimorphic loci, using Escherichia fergusonii as an out-group [53]. In 55\% of $E$. coli loci, and $36 \%$ of the B2 group loci, a matching segment with $E$. fergusonii was found (76\% identity on $90 \%$ of its length). This argues for the existence of a segment replacement in a fraction of the dimorphs. A comparable matching could not be performed for the two other species due to the absence of a sufficiently proximal genome out-group.

Homeologous loci represented 9 to $30 \%$ of the total loci (see Figure 5 for an example of such an homeologous locus). Interestingly, the longer the maximal MUMi genomic distance among the strains being compared, the higher the proportion of divergent loci among the total VSs. This may suggest that the yield of divergent loci reflects the evolutionary time elapsed from the time that the species diverged. The homeologous loci were significantly enriched among the intragenic loci for two alignments: E. coli $(53 \%$ of intragenic loci are homeologous, compared to $30 \%$ homeologous loci overall, $P<<0.01$ ), and $S$. aureus (33\% compared to $23 \%, P=0.017)$. This was not the case, however, for the B2 E. coli alignment ( $14 \%$ compared to $9 \%, P=0.08$ ), or the $S$. pyogenes alignment, where $23 \%$ of intragenic loci are homeologous, compared to $20 \%$ overall.

The polymorphic loci included 4 to $31 \%$ of all microdiversity loci, and may correspond to recombination hotspots, which remain to be studied in detail.

We then proceeded to test whether the two most important categories identified with the five-genome alignments, namely dimorphic and homeologous loci, were conserved when more genomes were included in the alignment. This proved to be the case (Table 2). For the $E$. coli and the $S$. pyogenes alignments, the homeologous loci even became preponderant relative to the dimorphic loci. 
In conclusion, microdiversity loci correspond mostly to cases of segment replacement, recombination hot spots, or to homeologous DNA that diverged faster relative to the backbone DNA. Cases of simple deletion or insertions were scarce, proportionally.

\section{Discussion}

\section{Microdiversity constitutes a major type of variability} between bacterial genomes within a species

The main outcome of this study is the discovery of a major type of bacterial genome diversity at the species level, made of variable short segments between 20 and $500 \mathrm{bp}$ long. In the five-genome alignments, these VSs represent some 63 to $72 \%$ of all possible variable regions detected by whole genome alignments. They remain very abundant (50 to $72 \%$ of all loci) when a maximal number of genomes are included in the alignments (Table 2). The presence of such small diversity had been reported earlier for E. coli [4,58], and its general importance is presently emerging in various comparative genomic studies, both in eukaryotes [59] and prokaryotes [60], where it is often reported as indels. However, the term indel is imprecise with respect to the size of segments involved (it can be used for 1- to 10-bp insertions or deletions up to the insertion or deletion of genomic islands). It is also misleading in terms of the underlying mechanism because it suggests that an insertion or a deletion occurred. Our work shows that more than $80 \%$ of the microdiversity loci are due to neither insertion nor deletion. The term indel was therefore replaced in this study by the more neutral term of microdiversity. If such microdiversity were found essentially outside genes, it might be considered as recombination scars, with little evolutionary importance. However, among the five-genome alignments, 35 to $55 \%$ of microdiversity regions lie within ORFs and 16 to 33\% of VSs are immediately upstream of ORFs. They should therefore contribute greatly to strain diversity within a species, either by affecting protein domains or by changing gene expression.

Among the E. coli genes harboring microdiversity, those encoding membrane and surface proteins are significantly enriched in VSs. This is in keeping with the notion that bacteria adapt to their varying and challenging environments by modifying their surface proteins, as already documented [61]. A comparative genome analysis detected 23 genes that are under positive selection in E. coli [62]. The present study identifies six of them $(f h u A, o m p A, o m p C, o m p F, \operatorname{lamB}$ and $u b i F)$ as harboring microdiversity. Moreover, for five of the six proteins where the structure is known, the Peterson analysis revealed that all mutations were concentrated on one or a few loops of the protein [62]; this feature allowed us to detect them in our screen, as scattered mutations would have gone undetected. Recently, using a more sensitive approach, 290 core genes of $E$. coli were detected as under short-term positive selection [63]. However, only four of them (narH, fes, cstA and $y p h H$ ) corresponded to the 192 genes we report here as harboring microdiversity. Therefore, at least 10 of the 192 genes harboring microdiversity may be under positive selection. Interestingly, microdiversity regions have been found in orthologous proteins compared broadly across bacterial and yeast species and found to be more numerous in essential proteins, which suggests a functional role for these flexible regions [60].

\section{Illegitimate recombination may explain a large fraction of the VSs}

One aim of this study was to elucidate the mechanisms underlying DNA recombination in microbial genomes. To this end, we focused on E. coli, the best studied bacterial species at the molecular level for recombination. More than half of the VS loci could not be explained by site-specific recombination, nor by transposition, nor by the hypothetical mechanism invoked for very short dispersed elements similar to PUs [29] (Table 2). We speculate that homologous or illegitimate recombination may explain these loci: in the three species, analysis of the five-genome alignments have shown that 10 to $18 \%$ of the VSs are flanked by repeats at least 5 bp long, which might account for part of the variability, especially as a deletion was often found associated with such loci (Table 4). However, as most repeats were of a size below $30 \mathrm{bp}$, the reported threshold for RecA-dependent homologous recombination in E. coli [64], it is likely that VSs are generated by replication slippage between the repeats, a mechanism also called short-homologydependent illegitimate recombination [65]. Although not as proportionally abundant as events detected in a previous, more limited study [50], the present analysis implicates short-homology-mediated deletion events as one significant cause of genome variability.

This conclusion on the importance of illegitimate recombination with regards to the VSs should not yield to the notion that homologous recombination is unimportant in bacterial genomes. Rather, homologous recombination relies on the detection of subtle tracts of 3 to $4 \%$ diverged sequences, which are not taken into account in our VS analysis. These sequences are part of the backbone, and studies on backbone DNA detecting blocks of mutations moving together across strains have shown, to the contrary, that homologous recombination plays a great role in bacteria. In E. coli, the average size of these blocks was estimated to be $500 \mathrm{bp}$ in a first study on four genomes [66], and more recently re-estimated to to $50 \mathrm{bp}$ based on a 20-genome comparison 
[53]. It has also been demonstrated that genomic islands, once integrated into a genome (by site-specific recombination most likely), diffuse in a population by homologous recombination between the sequences flanking the island [9].

Dimorphic loci, which contain exactly two different segments at a given site, represent 38 to $68 \%$ of all loci in the five-genome alignments (Figure 6), and 22 to $52 \%$ of all microdiversity loci in the maximal alignments (Table 2). In the case of the E. coli five-genome alignment, we found that in about half the cases, one of the two segments was present in E. fergusonii. This suggests that the ancestral segment was replaced at some point by another segment. A process called 'illegitimate recombination assisted by homology' can produce such a situation [67-69]. If the new incoming DNA segment is flanked by a segment homologous to the recipient chromosome, RecA may initiate homologous recombination on part of the molecule, followed by 'illegitimate' actors that complete the DNA integration at the other extremity (Figure 7a). Such a process is described in Streptococcus pneumoniae, Acinetobacter baylii and Pseudomonas stutzeri, three naturally competent species, and was found to be $10^{2}$ - to $10^{5}$-fold more efficient than strict illegitimate recombination [67-69]. Whether such a process could occur in $E$. coli, for instance during DNA conjugation, is presently under study. Alternatively, dimorphic (as well as polymorphic) loci may also correspond to fragile sites of the chromosome, which are hot spots of illegitimate recombination.

Although illegitimate recombination occurs at low frequency, our analysis of VSs suggests that it nevertheless is responsible for a large proportion of the genomic diversity: taking all loci differing from known events for E. coli, and labeled "Other" in Table 3, and removing the category of homeologous loci (Figure 6) we estimate that it is responsible for $41 \%$ (E. coli five-genome alignment) to $56 \%$ ( $E$. coli $\mathrm{B} 2$ alignment) of microdiversity loci.

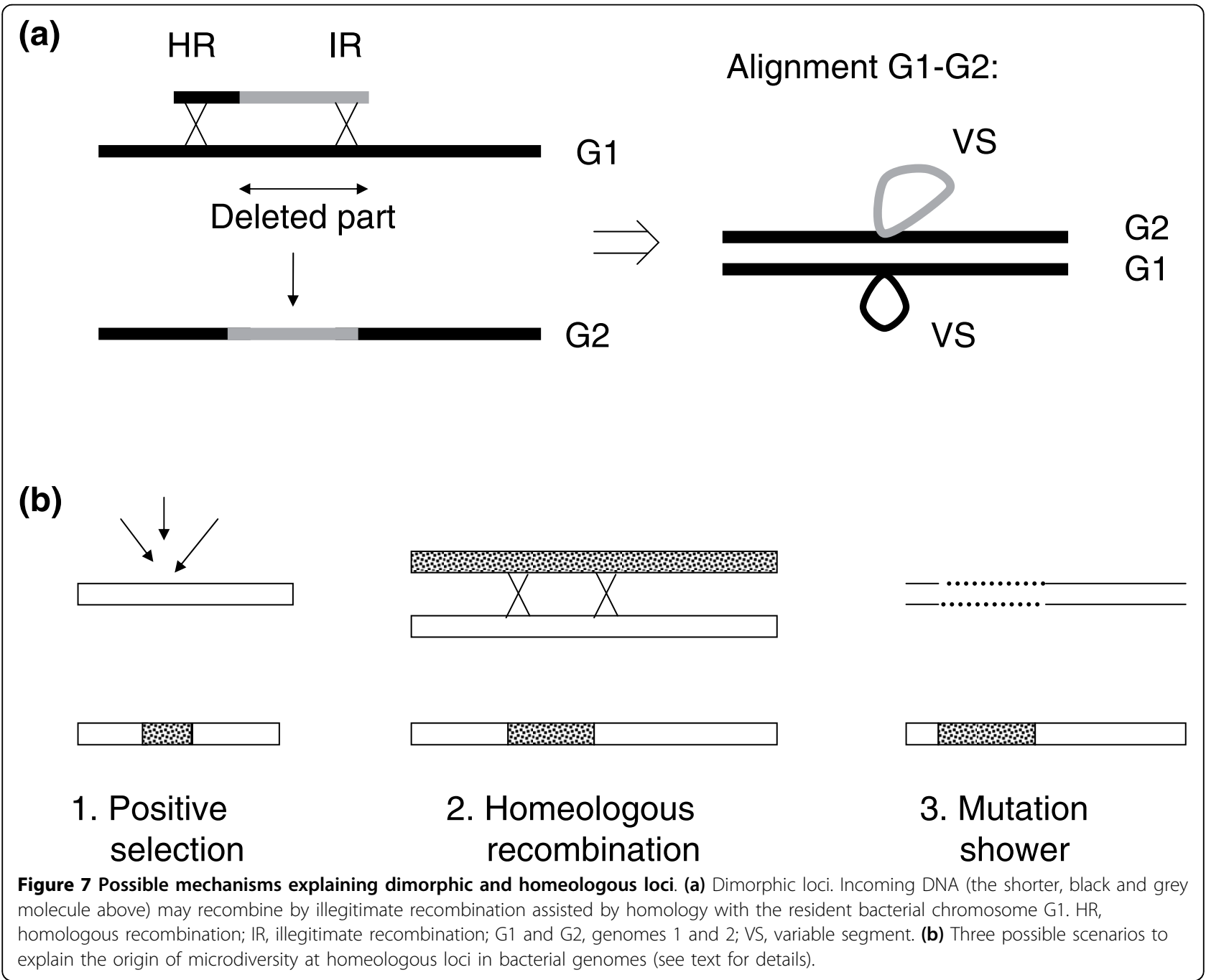




\section{What mechanism generates homeologous DNA microdiversity?}

A particular class of loci comprises those containing homeologous sequences. For E. coli, S. aureus and S. pyogenes, they represent 20 to $30 \%$ of loci in the fivegenome alignments, and even more (20 to $46 \%$ ) in the maximal genome alignments (Table 2). They are less abundant, however, in the alignment of B2 genomes (9\%). Interestingly, we found that among the five-genome alignments, homeologous loci were significantly enriched among intragenic loci (50 to $78 \%$ of the divergent loci are intragenic). The question arises as to how such blocks of microdiversity could be generated. Three scenarios are considered: positive selection, homeologous recombination and mutation showers (Figure $7 \mathrm{~b}$ ).

\section{Positive selection}

A given protein domain may be under positive selection, so that non-synonymous mutations accumulate in a limited region of the corresponding gene, while conservation of the rest of the protein is selected by physical constraints (for example, membrane-spanning domains), such that non-synonymous mutations are counterselected. In contrast, synonymous mutations are expected in equal density inside and outside the microdiversity block. However, we did not observe this pattern (synonymous mutations were also enriched in the homeologous loci), and therefore tend to exclude this hypothesis.

\section{Homeologous recombination between diverged DNA segments}

Given our similarity threshold, recombination should have taken place between at least $24 \%$ diverged sequences. In $E$. coli, RecA seems inefficient on $22 \%$ diverged sequences [70], and B. subtilis RecA is apparently inhibited by $7 \%$ divergence [71]. However, phage recombinases may be more efficient on highly diverged DNA [70]. Moreover, it is suspected that, in nature, bacteria alternate between a mutator and non-mutator state, via the inactivation/activation of the mutS or mutL genes, and during the mutator period, homeologous recombination should increase [72].

\section{Mutation showers}

High mutation densities are sometimes observed both in eukaryotes [73] and prokaryotes [74], and it is suggested that local exposure to a mutagenic agent, or a long state as single strand DNA may result in such mutation showers [75].

\section{Conclusions}

We report here an attempt to examine systematically genome variability at the DNA level in several bacterial species. We have shown that at the species level, the main kind of genomic variability is 'microdiversity'. It consists of small blocks (20 to $500 \mathrm{bp}$ in length) of
DNA, often present within or upstream of genes and contributing to the genome diversity. This notion raises the question of the mechanisms that may generate such diversity, and opens challenging new questions at both the molecular and bacterial evolution level.

\section{Materials and methods \\ Genomes}

All publicly available complete sequences and annotations were downloaded from the Genome Reviews database [76]. S. aureus genomes: Mu50 [GenBank: BA000017], MW2 [GenBank:BA000033], COL [GenBank:CP000046], RF122 [GenBank:AJ938182], MRSA252 [GenBank:BX571856], N315 [GenBank:BA000018], JH1 [GenBank:CP000736], MSSA476 [GenBank:BX571857], NCTC8325 [GenBank:CP000253], Newman [GenBank: AP009351], USA300 [GenBank:CP000255]. S. pyogenes genomes: M1 GAS, also known as SF370 [GenBank: AE004092], GAS315 [GenBank:NC004070], GAS8232 [GenBank:NC003485], GAS2096 [GenBank:NC008023], GAS10270 [GenBank:NC008022], GAS9429 [GenBank: CP000259], GAS10750 [GenBank:CP000262], NZ131 [GenBank:CP000829], GAS5005 [GenBank:CP000017], GAS6180 [GenBank:CP000056], GAS10394 [GenBank: CP000003], Manfredo [GenBank:AM295007]. E. coli genomes: K-12 MG1655 [GenBank:U00096], O157:H7 Sakai [GenBank:BA000007], B2 phylogenetic group, strain CFT073 [GenBank:AE014075], B2 group, strain UTI89 [GenBank:CP000243], B2 group, strain APECO1 [GenBank:CP000468], B2 phylogenetic group, strain 536 [GenBank:CP000247], B2 phylogenetic group, strain S88 [GenBank:CU928161], W3110 [GenBank:AP009048], DH10B [GenBank:CP000948], BW2952 [GenBank: CP001396], REL606 [GenBank:CP000819], BL21 [GenBank:AM946981], HS [GenBank:CP000802], Crooks [GenBank:CP000946], 55989 [GenBank:CU928145], E24377A [GenBank:CP000800], SE11 [GenBank: AP009240], EDL933 [GenBank:AE005174], TW14359 [GenBank:CP001368], 4115 [GenBank:CP001164], SMS3-5, named SECEC here [GenBank:CP000970], IAI39 [GenBank:CU928164], B2 phylogenetic group, E2348-69 [GenBank:FM180568]. All E. coli genome annotations were downloaded from the Genoscope ColiScope project [77], and their annotations were homogenized using the MaGe annotation platform [78].

\section{Alignment strategies}

A first set of alignments involving few and collinear genomes were computed using the MGA software [2]. Genomes were selected so as to be representative of the species under study. For this, a genomic distance based on maximal unique matches (MUM) was calculated for all possible genome pairs [54], and neighbor-joining trees were built so as to choose the appropriate 
genomes. When several closely related genomes were available, the second criterion used was genome collinearity, as determined by Mummer plots [79]. MGA alignment parameters were fine-tuned as described [4]. Briefly, in a first step, detection of anchors composed of maximal exact matches of minimal length 50 bp common to all genomes was carried out. A subset of collinear anchors was then selected by a chaining algorithm. Next, these two steps were repeated in each interval framed by the chosen anchors, using a lower minimal length value of $20 \mathrm{bp}$ for the maximal exact matches. The remaining gaps of the alignment, if shorter in length than 3,000 bp, were treated with ClustalW.

MGA alignment outputs are stored in the MOSAIC database after a post-treatment step on the raw ClustalW results. This step is needed to define, among the ClustalW output files, those in which the alignment reflects common ancestry from those where different pieces of DNA are forced into an alignment. As described earlier [4], post-treatment parameters were chosen so as to classify as VSs all segments of a given locus, if at least two of them share less than $76 \%$ identity on $100 \%$ of the aligned length, or if a gap larger than $20 \mathrm{bp}$ is found in the alignment. This allowed a high sensitivity with respect to VS size, but also some flexibility with respect to overall DNA divergence. The choice of the $76 \%$ threshold for DNA identity is described in Additional file 2. The 20-bp gap size was chosen as corresponding, at the protein level, to a small secondary structure of at least six amino acids. The minimal VS size was set to $20 \mathrm{bp}$. We compared the results obtained when the minimal VS size was increased from 20 to $42 \mathrm{bp}$ for a three-strain $E$. coli and a six-strain $S$. aureus alignment (alignments computed in the preparatory phase of this analysis). This resulted in a $26 \%$ decrease in the global number of loci. This indicated that an important proportion of VSs belongs to microdiversity loci, and justified our choice to maintain the minimal VS size as $20 \mathrm{bp}$, so as to be more sensitive to the microdiversity loci that may contribute to strain diversity.

A second set of alignments were computed so as to include a maximal number of genomes for the E. coli, $S$. aureus, and $S$. pyogenes species, using MAUVE version 1.2.3 for S. aureus and S. pyogenes [1], and progressive MAUVE version 2.1.3 for E. coli, instead of MGA for the first step. The same MOSAIC post-treatment step as described above was then applied [5]. Compared to MGA, the MAUVE software offers the advantages of dealing with large rearrangements, and the possibility to treat high numbers of genomes. This comes, however, at the price of slightly less precise backbone/VS boundaries, as we observed when comparing output from MGA versus MAUVE version 1.2.3 for an E. coli MG1655-Sakai alignment. Analyses requiring precise VS boundaries, such as repeat detection and positions of VSs relative to genes, were thus restricted to the MGA alignments. The phylogenetic trees corresponding to the strains used for the alignments are shown in Additional file 1.

\section{Collection of additional annotations for the E. coli genomes \\ Bacteriophages}

Phage coordinates of strains MG1655 and Sakai were downloaded from the Sakai genome project web page [80]. For the CFT073, UTI89 and 536 genomes, the Prophinder tool [19] and web access were used [81].

\section{CRISPR sequences}

Positions of the CRISPR sequences were retrieved from the CRISPR database of G Vergnaud's laboratory [82].

\section{Genomic islands}

Ou et al. [16] described a systematic means to detect genomic islands. Coordinates were downloaded from the supplementary data provided by them for MG1655, Sakai and CFT073 genomes. For the other genomes, an approach similar to that of Ou et al. based on synteny break points was used. Briefly, blocks of genes at least 5 $\mathrm{kb}$ long and not following the local synteny are analyzed for exceptional GC content or interpolated variable order motif (IVOM) value [83], presence of flanking tRNA genes, and presence of integrase-like genes. All blocks meeting at least one of the criteria were considered as regions of genomic plasticity, a denomination that does not make any assumption about the evolutionary origin or genetic basis of these variable chromosomal segments. The regions corresponding to bacteriophages and CRISPRs as defined above were then removed, and counted separately.

\section{Insertion sequences}

For all genomes but S88, UMN026 and IAI1, IS coordinates were taken from the ASAP site [84]. For the three remaining genomes, ISs were detected by the presence of transposase genes.

\section{Palindromic units/repetitive sequence elements}

PUs, also called repetitive sequences, have been described for E. coli [30]. Their coordinates on MG1655 were calculated starting from the Bachelier web page [85], and converting the coordinates so that they match with the current version of the MG1655 genome. Detection of putative PUs on the other E. coli genomes was performed as follows. PUs being palindromic, the presence of half a PU was searched using fuzznuc (EMBOSS package), with the following pattern ' [ACG] [AT] [TC]GCC [GT]GATGCGN $(3,9) C G[C T](0,1)$ CTTATC [CA] GGCCTAC [AG]' allowing for a maximum of four mismatches. PUs are often associated in pairs, which form bacterial interspersed mosaic 
elements. PUs separated by less than 100 bp were therefore associated in a unique mosaic element. Application of this pattern to the MG1655 complete genome allows detection of $80 \%$ of the 266 PUs or mosaics described in [85].

\section{Minisatellites}

Genomes were searched for tandemly repeated sequences on the minisatellite database of G Vergnaud's laboratory [86]. Parameters used were repeat motifs at least $20 \mathrm{bp}$ long, repeated at least twice, such that identity between repeats is at least $90 \%$. Among the minisatellites, a majority corresponded to PU elements that were scored separately (see above), so that only the remaining, non-PU minisatellites were reported in this category.

\section{Source of other E. coli variable segment}

For all E. coli VSs that did not correspond to the above mentioned annotations, an estimation of their content was carried out using Blast against the EMBL NonRedundant database, and the result was considered positive if at least $90 \%$ identity over at least $90 \%$ of the length was obtained. Results were parsed using the following categories: DNA segment present in at least one other E. coli strain (except very close kin such as EDL933, which is clonally related to the Sakai strain, or W3110, related to MG1655); DNA segment present in another bacterial species or a non-cultivable sample; no match in the Non-Redundant database.

\section{Variable segment analysis Data preparation}

Coordinates of the VSs for all four alignments were downloaded from the MOSAIC web site [55]. A script written in Python allowed us to analyze the VSs, in which the central object was the 'locus' class, composed of all VSs belonging to the same locus. Boundaries of some of the VSs as generated by the aligner were sometimes inexact, in the sense that the DNA content of the boundary (usually not more than 20 to $100 \mathrm{bp}$ ) was more than $90 \%$ identical in all VSs. A pre-treatment of the VS arrays was therefore performed to trim such boundaries (and sometimes remove a VS when its size shrank below $20 \mathrm{bp}$ ). As a result, some of the VSs described in the MOSAIC interface are slightly larger than those considered in this study.

\section{Inspection of variable segment boundaries relative to backbone genes}

For all VSs, a right and left neighboring gene on the backbone was assigned (the neighbor gene either overlapped the VS or was the first gene next to it). The position of all VSs of a given locus, relative to these genes, was then analyzed. If all VSs were inside genes, meaning that the ORF of the genes in all genomes was not interrupted by any of the VSs of the locus, the locus was labeled intragenic. If all VSs were between two genes that did not overlap with the VS boundaries, the locus was labeled intergenic. A flanking gene on the backbone was considered as missing if, among all VSs of the locus, the distance between one VS boundary and its neighboring gene distal extremity varied by more than $500 \mathrm{bp}$ (that is, the approximate size of a small gene). When the flanking gene overlapped with a VS boundary, the gene portion lying inside the VS was compared with all VSs: if this portion varied by more than $50 \mathrm{bp}$ (approximately 16 amino acids), it was considered that the locus modified the length of the flanking gene. If the neighbor genes overlapped the VS by less than these $50 \mathrm{bp}$, the overlapping was considered negligible and the locus was considered as intergenic.

\section{Detection of repeats flanking variable segments}

For all VSs, a DNA fragment encompassing the VS and $500 \mathrm{bp}$ flanking each side was extracted. Repeat detection was done with the Vmatch software [87], using a three step procedure. First, VS boundaries were scanned for the presence of repeats of length $=11 \mathrm{bp}$, allowing $10 \%$ divergence between the repeats, and a misplacement of the repeat of $10 \mathrm{bp}$ around the position of the VS boundary. If no repeat was found, a second search of repeats of length $>10 \mathrm{bp}$ with a Hamming distance of 1 was carried out. A final scan was done in case of repeat detection failure, for exact repeats $\geq 5$ bp (this value was chosen based on an example of a known, accurate deletion of genes yaf $N$ and yafO that occurred between a 5-bp repeat in the CFT073 strain of E. coli), allowing no misplacement relative to the VS boundary (otherwise, the probability to find such repeats at random is too high). This last step was found to double the number of VSs flanked by repeats.

\section{Detection of variable segments with similar DNA content}

To determine which VSs of a locus had similar content, pairwise alignments on VSs having similar lengths $( \pm 10 \%)$ were performed using 'stretcher' (EMBOSS suite). A similar content was attributed if more than $76 \%$ identity was found over at least $90 \%$ of the smaller VS length. A final step controlled that all relationships within the locus were transitive.

Additional file 1: Neighbor joining trees based on genomic MUMi distances of the strains selected for the maximal genomes alignments.

Additional file 2: Choice of the maximum divergence level for inclusion of ClustalW aligned sequences into the backbone.

Additional file 3: Distribution of the VS sizes in the five-genome alignments.

Additional file 4: List of genes containing microdiversity loci in the E. coli five-genome alignments.

Additional file 5: List of genes containing microdiversity loci in the E. coli B2 five-genome alignments.

Additional file 6: List of genes containing microdiversity loci in the S. aureus five-genome alignments. 
Additional file 7: List of genes containing microdiversity loci in the S. pyogenes five-genome alignments.

Additional file 8: Distribution of the E. coli genes containing microdiversity loci in functional categories.

Additional file 9: List of genes placed downstream of microdiversity loci in the E. coli five-genome alignments.

Additional file 10: List of genes placed downstream of microdiversity loci in the E. coli B2 five-genome alignments.

Additional file 11: List of genes placed downstream of microdiversity loci in the $S$. aureus five-genome alignments.

Additional file 12: List of genes placed downstream of microdiversity loci in the $S$. pyogenes five-genome alignments.

Additional file 13: Distribution of the E. coli genes placed downstream of microdiversity loci in functional categories.

Additional file 14: Loci occupancy in the five-genome alignments.

\section{Abbreviations}

bp: base pair; CRISPR: clustered: regularly interspaced short palindromic repeat; IS: insertion sequence; ORF: open reading frame; PU: palindromic unit; VS: variable segment.

\section{Acknowledgements}

We are thankful to Alexandra Gruss and Ivan Matic for helpful comments on the manuscript. We thank Hélène Chiapello, Annie Gendrault and Philippe Palcy for running MGA and MAUVE alignments and integrating them into the MOSAIC database [55], as well as the Migale bioinformatics platform for providing computational resources and technical assistance. The research was funded by the French 'Agence Nationale de la Recherche' project CoCoGen BLAN07-1_185484.

\section{Author details}

${ }^{1}$ INRA, UMR1319, Micalis, Bat 222, Jouy en Josas, 78350, France. ${ }^{2}$ INSERM U722 and Université Paris 7, Faculté de Médecine, Site Xavier Bichat, Paris, 75018, France. ${ }^{3}$ CNRS-UMR 8030 \& CEA/IG/Genoscope, Laboratoire d'Analyses Bioinformatiques en Génomique et Métabolisme (LABGeM), rue Gaston Crémieux, Evry, 91057, France. ${ }^{4}$ CEA, Institut de Génomique, Genoscope, rue Gaston Crémieux, Evry, 91057, France.

\section{Authors' contributions}

FT performed the analysis of maximal genome alignments, MAP conceived the work, performed it, and wrote the manuscript. ED, CM and VB were responsible for the complete sequencing and annotation of seven strains of Escherichia (Coliscope project), and made their data available prior to publication. MEK contributed to the work and ED and MEK contributed to the manuscript.

Received: 29 October 2009 Revised: 15 March 2010

Accepted: 30 April 2010 Published: 30 April 2010

\section{References}

1. Darling AC, Mau B, Blattner FR, Perna NT: Mauve: multiple alignment of conserved genomic sequence with rearrangements. Genome Res 2004, 14:1394-1403.

2. Hohl M, Kurtz S, Ohlebusch E: Efficient multiple genome alignment. Bioinformatics 2002, 18(Suppl 1):S312-320.

3. Treangen TJ, Messeguer X: M-GCAT: interactively and efficiently constructing large-scale multiple genome comparison frameworks in closely related species. BMC Bioinformatics 2006, 7:433.

4. Chiapello H, Bourgait I, Sourivong F, Heuclin G, Gendrault-Jacquemard A, Petit MA, El Karoui M: Systematic determination of the mosaic structure of bacterial genomes: species backbone versus strain-specific loops. BMC Bioinformatics 2005, 6:171.

5. Chiapello H, Gendrault A, Caron C, Blum J, Petit MA, El Karoui M: MOSAIC: an online database dedicated to the comparative genomics of bacterial strains at the intra-species level. BMC Bioinformatics 2008, 9:498.
6. Hayashi T, Makino K, Ohnishi M, Kurokawa K, Ishii K, Yokoyama K, Han CG, Ohtsubo E, Nakayama K, Murata T, Tanaka M, Tobe T, lida T, Takami H, Honda T, Sasakawa C, Ogasawara N, Yasunaga T, Kuhara S, Shiba T, Hattori $\mathrm{M}$, Shinagawa $\mathrm{H}$ : Complete genome sequence of enterohemorrhagic Escherichia coli 0157:H7 and genomic comparison with a laboratory strain K-12. DNA Res 2001, 8:11-22.

7. Vernikos GS, Parkhill J: Resolving the structural features of genomic islands: a machine learning approach. Genome Res 2008, 18:331-342.

8. Gill SR, Fouts DE, Archer GL, Mongodin EF, Deboy RT, Ravel J, Paulsen IT, Kolonay JF, Brinkac L, Beanan M, Dodson RJ, Daugherty SC, Madupu R, Angiuoli SV, Durkin AS, Haft DH, Vamathevan J, Khouri H, Utterback T, Lee C, Dimitrov G, Jiang L, Qin H, Weidman J, Tran K, Kang K, Hance IR, Nelson $K E$, Fraser $C M$ : Insights on evolution of virulence and resistance from the complete genome analysis of an early methicillin-resistant Staphylococcus aureus strain and a biofilm-producing methicillinresistant Staphylococcus epidermidis strain. J Bacteriol 2005, 187:2426-2438.

9. Schubert S, Darlu P, Clermont O, Wieser A, Magistro G, Hoffmann C, Weinert K, Tenaillon O, Matic I, Denamur E: Role of intraspecies recombination in the spread of pathogenicity islands within the Escherichia coli species. PLoS Pathog 2009, 5:e1000257.

10. Chen J, Novick RP: Phage-mediated intergeneric transfer of toxin genes. Science 2009, 323:139-141.

11. Tormo MA, Ferrer MD, Maiques E, Ubeda C, Selva L, Lasa I, Calvete JJ, Novick RP, Penades JR: Staphylococcus aureus pathogenicity island DNA is packaged in particles composed of phage proteins. J Bacteriol 2008, 190:2434-2440.

12. Brochet M, Rusniok C, Couve E, Dramsi S, Poyart C, Trieu-Cuot P, Kunst F, Glaser $P$ : Shaping a bacterial genome by large chromosomal replacements, the evolutionary history of Streptococcus agalactiae. Proc Natl Acad Sci USA 2008, 105:15961-15966.

13. Burrus $V$, Pavlovic G, Decaris B, Guedon G: Conjugative transposons: the tip of the iceberg. Mol Microbiol 2002, 46:601-610.

14. Hsiao W, Wan I, Jones SJ, Brinkman FS: IslandPath: aiding detection of genomic islands in prokaryotes. Bioinformatics 2003, 19:418-420.

15. Mantri Y, Williams KP: Islander: a database of integrative islands in prokaryotic genomes, the associated integrases and their DNA site specificities. Nucleic Acids Res 2004, 32:D55-58.

16. Ou HY, Chen LL, Lonnen J, Chaudhuri RR, Thani AB, Smith R, Garton NJ, Hinton J, Pallen M, Barer MR, Rajakumar K: A novel strategy for the identification of genomic islands by comparative analysis of the contents and contexts of tRNA sites in closely related bacteria. Nucleic Acids Res 2006, 34:e3.

17. Bose M, Barber RD: Prophage Finder: a prophage loci prediction tool for prokaryotic genome sequences. In Silico Biol 2006, 6:223-227.

18. Fouts DE: Phage_Finder: automated identification and classification of prophage regions in complete bacterial genome sequences. Nucleic Acids Res 2006, 34:5839-5851.

19. Lima-Mendez G, Van Helden J, Toussaint A, Leplae R: Prophinder: a computational tool for prophage prediction in prokaryotic genomes. Bioinformatics 2008, 24:863-865.

20. Barrangou R, Fremaux C, Deveau H, Richards M, Boyaval P, Moineau S, Romero DA, Horvath P: CRISPR provides acquired resistance against viruses in prokaryotes. Science 2007, 315:1709-1712.

21. Marraffini LA, Sontheimer EJ: CRISPR interference limits horizontal gene transfer in staphylococci by targeting DNA. Science 2008, 322:1843-1845.

22. Bland C, Ramsey TL, Sabree F, Lowe M, Brown K, Kyrpides NC, Hugenholtz P: CRISPR recognition tool (CRT): a tool for automatic detection of clustered regularly interspaced palindromic repeats. $B M C$ Bioinformatics 2007, 8:209.

23. Grissa I, Vergnaud G, Pourcel C: The CRISPRdb database and tools to display CRISPRs and to generate dictionaries of spacers and repeats. BMC Bioinformatics 2007, 8:172.

24. Siguier P, Perochon J, Lestrade L, Mahillon J, Chandler M: ISfinder: the reference centre for bacterial insertion sequences. Nucleic Acids Res 2006, 34:D32-36.

25. Wagner A, Lewis $C$, Bichsel M: A survey of bacterial insertion sequences using IScan. Nucleic Acids Res 2007, 35:5284-5293.

26. Zhou F, Olman V, Xu Y: Insertion Sequences show diverse recent activities in Cyanobacteria and Archaea. BMC Genomics 2008, 9:36. 
27. Chang $\mathrm{CH}$, Chang YC, Underwood A, Chiou CS, Kao CY: VNTRDB: a bacterial variable number tandem repeat locus database. Nucleic Acids Res 2007, 35:D416-421.

28. Denoeud F, Vergnaud G: Identification of polymorphic tandem repeats by direct comparison of genome sequence from different bacterial strains: a web-based resource. BMC Bioinformatics 2004, 5:4.

29. Elhai J, Kato M, Cousins S, Lindblad P, Costa JL: Very small mobile repeated elements in cyanobacterial genomes. Genome Res 2008 18:1484-1499.

30. Gilson E, Saurin W, Perrin D, Bachellier S, Hofnung M: The BIME family of bacterial highly repetitive sequences. Res Microbiol 1991, 142:217-222.

31. Valens M, Penaud S, Rossignol M, Cornet F, Boccard F: Macrodomain organization of the Escherichia coli chromosome. EMBO J 2004, 23:4330-4341.

32. Anderson RP, Roth JR: Tandem genetic duplications in phage and bacteria. Annu Rev Microbiol 1977, 31:473-505.

33. Lovett ST, Drapkin PT, Sutera VA Jr, Gluckman-Peskind TJ: A sister-strand exchange mechanism for recA-independent deletion of repeated DNA sequences in Escherichia coli. Genetics 1993, 135:631-642.

34. Bruand C, Bidnenko V, Ehrlich SD: Replication mutations differentially enhance RecA-dependent and RecA-independent recombination between tandem repeats in Bacillus subtilis. Mol Microbiol 2001, 39:1248-1258.

35. Marsin S, Mathieu A, Kortulewski T, Guerois R, Radicella JP: Unveiling novel $\mathrm{RecO}$ distant orthologues involved in homologous recombination. PLOS Genet 2008, 4:e1000146.

36. Smith GR: Conjugational recombination in E. coli : myths and mechanisms. Cell 1991, 64:19-27.

37. Claverys JP, Prudhomme M, Mortier-Barriere I, Martin B: Adaptation to the environment: Streptococcus pneumoniae, a paradigm for recombinationmediated genetic plasticity?. Mol Microbiol 2000, 35:251-259.

38. Chedin F, Dervyn E, Dervyn R, Ehrlich SD, Noirot P: Frequency of deletion formation decreases exponentially with distance between short direct repeats. Mol Microbiol 1994, 12:561-569.

39. Ikeda H, Shimizu H, Ukita T, Kumagai M: A novel assay for illegitimate recombination in Escherichia coli : stimulation of lambda bio transducing phage formation by ultra-violet light and its independence from RecA function. Adv Biophys 1995, 31:197-208.

40. Canceill D, Ehrlich SD: Copy-choice recombination mediated by DNA polymerase III holoenzyme from Escherichia coli. Proc Natl Acad Sci USA 1996, 93:6647-6652.

41. Canceill D, Viguera E, Ehrlich SD: Replication slippage of different DNA polymerases is inversely related to their strand displacement efficiency. $\mathrm{J}$ Biol Chem 1999, 274:27481-27490.

42. Viguera E, Canceill D, Ehrlich SD: Replication slippage involves DNA polymerase pausing and dissociation. EMBO J 2001, 20:2587-2595.

43. Vilette $D$, Uzest $M$, Ehrlich SD, Michel B: DNA transcription and repressor binding affect deletion formation in Escherichia coli plasmids. EMBO 1992, 11:3629-3634.

44. Ehrlich SD: Illegitimate recombination. Mobile DNA Washington, DC: American Society for MicrobiologyBerg D, Howe M 1989, 799-832.

45. Michel B: Illegitimate recombination in bacteria. Organization of the Prokaryotic Genome Washington DC: ASM PressCharlebois RL 1999, 129-150.

46. Della M, Palmbos PL, Tseng HM, Tonkin LM, Daley JM, Topper LM, Pitcher RS, Tomkinson AE, Wilson TE, Doherty AJ: Mycobacterial Ku and ligase proteins constitute a two-component NHEJ repair machine. Science 2004, 306:683-685.

47. Weller GR, Kysela B, Roy R, Tonkin LM, Scanlan E, Della M, Devine SK, Day JP, Wilkinson A, d'Adda di Fagagna F, Devine KM, Bowater RP, Jeggo PA, Jackson SP, Doherty AJ: Identification of a DNA nonhomologous end-joining complex in bacteria. Science 2002, 297:1686-1689.

48. Moeller R, Stackebrandt E, Reitz G, Berger T, Rettberg P, Doherty AJ, Horneck G, Nicholson WL: Role of DNA repair by nonhomologous-end joining in Bacillus subtilis spore resistance to extreme dryness, monoand polychromatic UV, and ionizing radiation. J Bacteriol 2007, 189.3306-3311.

49. Pitcher RS, Brissett NC, Doherty AJ: Nonhomologous end-joining in bacteria: a microbial perspective. Annu Rev Microbiol 2007, 61:259-282

50. Tsuru T, Kawai M, Mizutani-Ui Y, Uchiyama I, Kobayashi I: Evolution of paralogous genes: Reconstruction of genome rearrangements through comparison of multiple genomes within Staphylococcus aureus. Mol Biol Evol 2006, 23:1269-1285.

51. Le Gall T, Clermont O, Gouriou S, Picard B, Nassif X, Denamur E, Tenaillon O: Extraintestinal virulence is a coincidental by-product of commensalism in B2 phylogenetic group Escherichia coli strains. Mol Biol Evol 2007 24:2373-2384.

52. Lescat M, Hoede C, Clermont O, Garry L, Darlu P, Tuffery P, Denamur E, Picard B: aes, the gene encoding the esterase B in Escherichia coli, is a powerful phylogenetic marker of the species. BMC Microbiol 2009, 9:273.

53. Touchon $M$, Hoede $C$, Tenaillon $O$, Barbe $V$, Baeriswyl S, Bidet $P$, Bingen $E$, Bonacorsi S, Bouchier C, Bouvet O, Calteau A, Chiapello H, Clermont O, Cruveiller S, Danchin A, Diard M, Dossat C, Karoui ME, Frapy E, Garry L, Ghigo JM, Gilles AM, Johnson J, Le Bouguénec C, Lescat M, Mangenot $S$, Martinez-Jéhanne V, Matic I, Nassif X, Oztas S, et al: Organised genome dynamics in the Escherichia coli species results in highly diverse adaptive paths. PLoS Genet 2009, 5:e1000344.

54. Deloger M, El Karoui M, Petit MA: A genomic distance based on MUM indicates discontinuity between most bacterial species and genera. $J$ Bacteriol 2009, 191:91-99.

55. MOSAIC. [http://genome.jouy.inra.fr/mosaic].

56. Cramton SE, Schnell NF, Gotz F, Bruckner R: Identification of a new repetitive element in Staphylococcus aureus. Infect Immun 2000, 68:2344-2348.

57. Hardy KJ, Ussery DW, Oppenheim BA, Hawkey PM: Distribution and characterization of staphylococcal interspersed repeat units (SIRUs) and potential use for strain differentiation. Microbiology 2004, 150:4045-4052.

58. Perna NT, Plunkett G, Burland V, Mau B, Glasner JD, Rose DJ, Mayhew GF, Evans PS, Gregor J, Kirkpatrick HA, Pósfai G, Hackett J, Klink S, Boutin A, Shao Y, Miller L, Grotbeck EJ, Davis NW, Lim A, Dimalanta ET, Potamousis KD, Apodaca J, Anantharaman TS, Lin J, Yen G, Schwartz DC, Welch RA, Blattner FR: Genome sequence of enterohaemorrhagic Escherichia coli 0157:H7. Nature 2001, 409:529-533.

59. Volfovsky N, Oleksyk TK, Cruz KC, Truelove AL, Stephens RM, Smith MW: Genome and gene alterations by insertions and deletions in the evolution of human and chimpanzee chromosome 22. BMC Genomics 2009, 10:51.

60. Chan SK, Hsing M, Hormozdiari F, Cherkasov A: Relationship between insertion/deletion (indel) frequency of proteins and essentiality. BMC Bioinformatics 2007, 8:227.

61. Nunes A, Borrego MJ, Nunes B, Florindo C, Gomes JP: Evolutionary dynamics of ompA, the gene encoding the Chlamydia trachomatis key antigen. J Bacterio/ 2009, 191:7182-7192.

62. Petersen L, Bollback JP, Dimmic M, Hubisz M, Nielsen R: Genes under positive selection in Escherichia coli. Genome Res 2007, 17:1336-1343.

63. Chattopadhyay S, Weissman SJ, Minin VN, Russo TA, Dykhuizen DE, Sokurenko EV: High frequency of hotspot mutations in core genes of Escherichia coli due to short-term positive selection. Proc Natl Acad Sci USA 2009, 106:12412-12417.

64. Shen P, Huang HV: Homologous recombination in Escherichia coli : dependence on substrate length and homology. Genetics 1986 112:441-457.

65. Shimizu H, Yamaguchi $H$, Ashizawa $Y$, Kohno Y, Asami M, Kato J, Ikeda H: Short-homology-independent illegitimate recombination in Escherichia coli : distinct mechanism from short-homology-dependent illegitimate recombination. J Mol Biol 1997, 266:297-305.

66. Mau B, Glasner JD, Darling AE, Perna NT: Genome-wide detection and analysis of homologous recombination among sequenced strains of Escherichia coli. Genome Biol 2006, 7:R44.

67. de Vries J, Wackernagel W: Integration of foreign DNA during natural transformation of Acinetobacter sp. by homology-facilitated illegitimate recombination. Proc Natl Acad Sci USA 2002, 99:2094-2099.

68. Meier $P$, Wackernagel $W$ : Mechanisms of homology-facilitated illegitimate recombination for foreign DNA acquisition in transformable Pseudomonas stutzeri. Mol Microbiol 2003, 48:1107-1118.

69. Prudhomme M, Libante V, Claverys JP: Homologous recombination at the border: insertion-deletions and the trapping of foreign DNA in Streptococcus pneumoniae. Proc Natl Acad Sci USA 2002, 99:2100-2105.

70. Martinsohn JT, Radman M, Petit MA: The lambda red proteins promote efficient recombination between diverged sequences: implications for bacteriophage genome mosaicism. PLoS Genet 2008, 4:e1000065. 
71. Majewski J, Cohan FM: DNA sequence similarity requirements for interspecific recombination in Bacillus. Genetics 1999, 153:1525-1533.

72. Denamur E, Lecointre G, Darlu P, Tenaillon O, Acquaviva C, Sayada C, Sunjevaric I, Rothstein R, Elion J, Taddei F, Radman M, Matic I: Evolutionary implications of the frequent horizontal transfer of mismatch repair genes. Cell 2000, 103:711-721.

73. Wang J, Gonzalez KD, Scaringe WA, Tsai K, Liu N, Gu D, Li W, Hill KA, Sommer SS: Evidence for mutation showers. Proc Natl Acad Sci USA 2007, 104:8403-8408.

74. Drake JW: Mutations in clusters and showers. Proc Natl Acad Sci USA 2007, 104:8203-8204.

75. Yang Y, Sterling J, Storici F, Resnick MA, Gordenin DA: Hypermutability of damaged single-strand DNA formed at double-strand breaks and uncapped telomeres in yeast Saccharomyces cerevisiae. PLoS Genet 2008, 4:e1000264.

76. Kersey P, Bower L, Morris L, Horne A, Petryszak R, Kanz C, Kanapin A, Das U, Michoud K, Phan I, Gattiker A, Kulikova T, Faruque N, Duggan K, Mclaren P, Reimholz B, Duret L, Penel S, Reuter I, Apweiler R: Integr8 and Genome Reviews: integrated views of complete genomes and proteomes. Nucleic Acids Res 2005, 33:D297-302.

77. MaGe (Magnifying genomes) Microbial Genome Annotation System. [https://www.genoscope.cns.fr/agc/mage/wwwpkgdb/MageHome].

78. Vallenet D, Labarre L, Rouy Z, Barbe V, Bocs S, Cruveiller S, Lajus A, Pascal G, Scarpelli C, Medigue C: MaGe: a microbial genome annotation system supported by synteny results. Nucleic Acids Res 2006, 34:53-65.

79. Kurtz S, Phillippy A, Delcher AL, Smoot M, Shumway M, Antonescu C, Salzberg SL: Versatile and open software for comparing large genomes. Genome Biol 2004, 5:R12.

80. E. coli 0157:H7 Sakai Genome Project. [http://genome.naist.jp/bacteria/ 0157/overview.html].

81. ACLAME: Prophinder. [http://aclame.ulb.ac.be/Tools/Prophinder/].

82. CRISPRdb. [http://crispr.u-psud.fr/crispr/].

83. Vernikos GS, Parkhill J: Interpolated variable order motifs for identification of horizontally acquired DNA: revisiting the Salmonella pathogenicity islands. Bioinformatics 2006, 22:2196-2203.

84. ASAP. [http://asap.ahabs.wisc.edu/asap/home.php].

85. BIMEs Table. [http://www.pasteur.fr/recherche/unites/pmtg/repet/ tableauBIMEcoli.html].

86. The Microorganisms Tandem Repeat Database. [http://minisatellites.upsud.fr/GPMS/].

87. The Vmatch large scale sequence analysis software. [http://www.vmatch de/].

doi:10.1186/gb-2010-11-4-r45

Cite this article as: Touzain et al: Small variable segments constitute a major type of diversity of bacterial genomes at the species level.

Genome Biology 2010 11:R45.

\section{Submit your next manuscript to BioMed Central and take full advantage of:}

- Convenient online submission

- Thorough peer review

- No space constraints or color figure charges

- Immediate publication on acceptance

- Inclusion in PubMed, CAS, Scopus and Google Scholar

- Research which is freely available for redistribution

Submit your manuscript at www.biomedcentral.com/submit
Biomed Central 